\title{
Interlamellar Spacing of Pearlite in a Near-eutectoid Fe-C Alloy Measured by Serial Sectioning
}

\author{
Guohong ZHANG and Masato ENOMOTO \\ Department of Materials Science and Engineering, Ibaraki University, Nakanarusawa, Hitachi 316-8511 Japan. \\ E-mail: enomotom@mx.ibaraki.ac.jp
}

(Received on December 26, 2008; accepted on February 17, 2009)

\begin{abstract}
The interlamellar spacings of pearlite formed isothermally at 700 and $680^{\circ} \mathrm{C}$ in a near-eutectoid Fe$0.82 \mathrm{mass} \% \mathrm{C}$ alloy were measured by serial sectioning coupled with scanning electron and atomic force microscopy. The intersection angle of cememtite lamellae with the metallographic surface was determined from the variation of horizontal displacement of cementite lamellae with removal depth. The true lamellar spacing was then calculated from the apparent lamellar spacing on the surface. When the angle was small, i.e. less than $\sim 20^{\circ}$, it was measured directly by atomic force microscope. The minimum and mean true lamellar spacings are in good agreement with those measured by other methods. The distribution of interlamellar spacings on the specimen surface back calculated from the spectra of true interlamellar spacing assuming the random orientation of cementite lamellae was in fair agreement with the measured one. It is likely that the distribution of true lamellar spacings is primarily due to recalescence and the minimum true spacings rather than the mean value may be relevant to the thermodynamic theory of pearlite transformation.
\end{abstract}

KEY WORDS: pearlite; interlamellar spacing; serial sectioning; near-eutectoid alloy.

\section{Introduction}

The interlamellar spacing is one of the most important parameters that characterize pearlite because mechanical properties of pearlitic steel are strongly influenced by interlamellar spacing. At earlier times the interlamellar spacing of steel which underwent a certain heat treatment was considered to be uniform and equal to the minimum spacing observed on the metallographic surface. ${ }^{1)}$ However, it is now well known that the interlamellar spacing is not uniform, but has a considerable scatter from one colony to another $^{2-9)}$ and furthermore, it is not constant even in one colony. ${ }^{10-12)}$ Since Pellisier et al. ${ }^{2)}$ first showed that the interlamellar spacing was not constant in isothermally transformed pearlite, a number of methods have been proposed to determine the mean value ${ }^{3,13-15)}$ and the distribution of true interlamellar spacings, ${ }^{7,16,17)}$ coupling metallographic observation, e.g. optical and scanning microscopy, with stereological analysis. ${ }^{16,17)}$ As reviewed by Voort and Roosz, ${ }^{15)}$ in the stereological analyses spurious negative frequencies of interlamellar spacings are often observed in certain size classes unless the number of measurements is sufficiently large. Some authors attempted to directly determine the minimum value and the distribution of lamellar spacings under transmission electron microscopy (TEM), ${ }^{9,15)}$ scanning electron microscopy $(\mathrm{SEM})^{15)}$ and atomic force microscopy $(\mathrm{AFM})^{18)}$ by searching the special colony that appeared to be perpendicular to the specimen surface in deeply etching specimens.
Serial sectioning is a technique which makes possible the construction of 3-D microstructure of opaque metallic materials by computer. ${ }^{19,20)}$ Combining serial sectioning with measurement of topological properties and crystallographic analyses, a new area which may be called quantitative serial sectioning has been emerged. ${ }^{21)}$ The advantage of this technique is that one can eliminate assumptions as to the shape and distribution of the object, which are often made in 3-D characterization of microstructure by means of stereological analysis.

In this study direct measurement of true interlamellar spacing is attempted by serial sectioning coupled with SEM. The angle between the cementite lamellae and the metallographic surface is determined from the horizontal displacement of the lamellae as a function of removal depth. Since the edges of cementite lamellae are easily broken during polishing when the intersection angle is small, AFM is used to supplement the measurement at smaller angles of intersection, e.g. less than $\sim 20^{\circ}$. The measurements are made in a near-eutectoid $\mathrm{Fe}-0.82$ mass $\% \mathrm{C}$ alloy isothermally transformed at two temperatures. The mean value and the distribution of true lamellar spacings are determined. They are compared with those in the literature, e.g. the minimum and mean values, to check the viability of this technique. The physical reason for the scatter of lamellar spacings is also discussed on the basis of thermodynamic and kinetic considerations. 


\section{Experimental Procedure}

The chemical composition of the alloy (carbon steel containing $0.71 \mathrm{mass} \% \mathrm{Mn}$ and $0.23 \mathrm{mass} \% \mathrm{Si}$ ) is shown in Table 1. The calculated eutectoid temperature and composition are $722^{\circ} \mathrm{C}$ and $0.75 \% \mathrm{C}$, respectively. The alloy was homogenized at $1250^{\circ} \mathrm{C}$ for $48 \mathrm{~h}$ in a silica tube. Square specimens, $4 \times 10^{-3} \mathrm{~m}$ on a side and $1 \times 10^{-3} \mathrm{~m}$ thick, were austenitized for $10 \mathrm{~min}$ at $1100^{\circ} \mathrm{C}$ under an argon atmosphere and were swiftly moved into a salt bath for isothermal reaction to occur at 700 and $680^{\circ} \mathrm{C}$ for $2 \mathrm{~h}$. After isothermal holding, they were quenched into iced water.

Forty areas were selected systematically without bias, which contained $\sim 250$ colonies. Fiducial hardness indentations were applied in these areas after they were etched in $3 \%$ nital. SEM micrographs of the selected areas were taken for 6 consecutive sections. A series of micrographs in each area were aligned using Scion Image software. The removal depth for a given section $i(i=2 \sim 6)$ relative to section 1, $y$, was calculated from the diagonal-to-depth ratio by measuring the change in diagonal length of the indents after each polishing step. The horizontal displacements of cementite lamellae, $x$, were calculated by measuring the change of the perpendicular distance from the reference point (the centre of indentation) to the cementite lamellae in consecutive sections, as illustrated in Fig. 1. The intersection angle $\theta$ between the normals of cememtite lamellae and the specimen surface was determined from the equation,

Table 1. Chemical compositions of alloys studied.

\begin{tabular}{cc}
\hline \hline Element & mass\% \\
\hline \hline $\mathrm{C}$ & 0.82 \\
$\mathrm{Mn}$ & 0.71 \\
$\mathrm{Si}$ & 0.23 \\
$\mathrm{P}$ & 0.01 \\
$\mathrm{~S}$ & 0.005 \\
$\mathrm{Cr}$ & 0.02 \\
$\mathrm{Fe}$ & Bal. \\
\hline
\end{tabular}

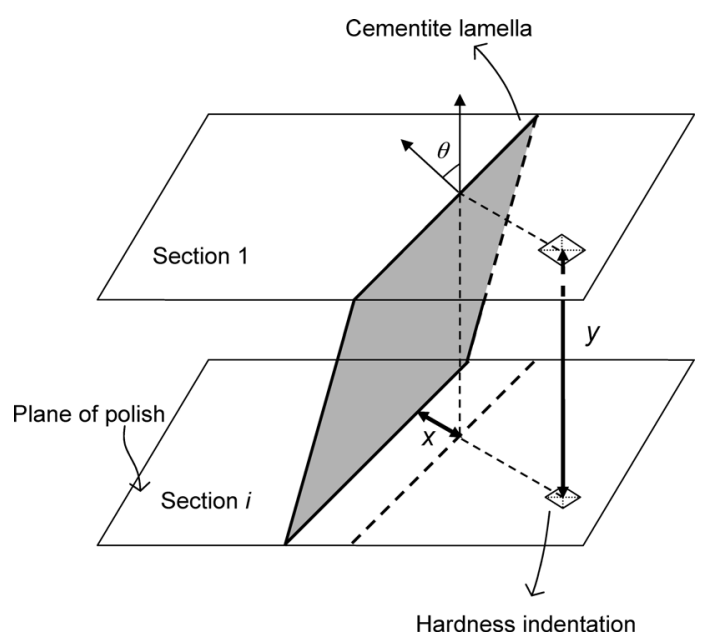

Fig. 1. Schematic illustration of horizontal displacement $x$ and removal depth $y$ for determination of intersection angle $\theta$ of cementite lamellae with metallographic surface.

$$
\theta=\tan ^{-1} \frac{y}{x}
$$

by least square method. The removal depth scatters considerably from one area to another on one section. However, on the average the sections were parallel to the original specimen surface. ${ }^{22)}$ The true interlamellar spacing $\lambda_{t}$ was then obtained from the apparent interlamellar spacing, $\lambda_{a}$, for each colony as,

$$
\lambda_{\mathrm{t}}=\lambda_{\mathrm{a}} \sin \theta
$$

Those colonies of small intersection angle and thus, having a larger apparent lamellar spacing, were observed by AFM equipped with an optical microscope with the probe tip of $\mathrm{Si}_{3} \mathrm{~N}_{4}$. It was operated at room temperature in air and by a constant-force mode (the force was $3.6 \mathrm{nN}$ ). The spring constant of cantilever was $0.12 \mathrm{~N} / \mathrm{m}$ and the scanning speed was about $100 \mu \mathrm{m} / \mathrm{s}$. The use of AFM was confined to the colonies of small intersection angle because the ferrite lamellae tend to form a deep recess so that the probe tip can not reach the bottom when the angle is large.

A circular test line method has been used to measure the mean true lamellar spacing $\bar{\lambda}_{\mathrm{t}}{ }^{14,15)}$ A test circle of diameter $d_{\mathrm{c}}$ is drawn in a single pearlite colony. The mean spacing in the direction perpendicular to the lamellae $\bar{\sigma}_{\mathrm{d}}$ is calculated from the equation,

$$
\bar{\sigma}_{\mathrm{d}}=\frac{d_{\mathrm{c}}}{n_{\mathrm{d}}}
$$

where $n_{\mathrm{d}}$ is the number of cementite lamellae intercepted by the diameter. Then, the mean interlamellar spacing can be calculated from the equation,

$$
\bar{\lambda}_{\mathrm{t}}=\frac{\pi}{4} \bar{\sigma}_{\mathrm{d}}
$$

This method was applied to the present specimens and results are compared with those obtained from serial sectioning technique.

\section{Results and Discussion}

\subsection{Distribution of Apparent Interlamellar Spacings}

Figure 2 shows the variation of apparent lamellar spacing $\lambda_{\mathrm{a}}$ with section number in two colonies of the specimen isothermally held at $700^{\circ} \mathrm{C}$. It is seen that the scatter of $\lambda_{\mathrm{a}}$ among the sections is not very large. Figures 3(a) and 3(b) illustrate the frequency distributions of $\lambda_{\mathrm{a}}$ in the specimens held at 700 and $680^{\circ} \mathrm{C}$, respectively. The width of the classes is $\Delta_{\lambda}=0.05 \mu \mathrm{m}$. In Table 2 are shown the observed minimum $\lambda_{\mathrm{a}}^{\min }$ and maximum $\lambda_{\mathrm{a}}^{\max }$ lamellar spacings at these temperatures. If all the colonies have a uniform lamellar spacing, corresponding to, say, a minimum spacing $\lambda_{\mathrm{a}}^{\mathrm{min}}$, the frequencies in each size class decrease rapidly with increasing $\lambda_{\mathrm{a}}$ values. ${ }^{2,23)}$ Since the measured distribution passes through a maximum in the $3 \mathrm{rd}$ and 2 nd size class, see Figs. 3(a) and 3(b), it is clear that the true lamellar spacing is not uniform among colonies. 


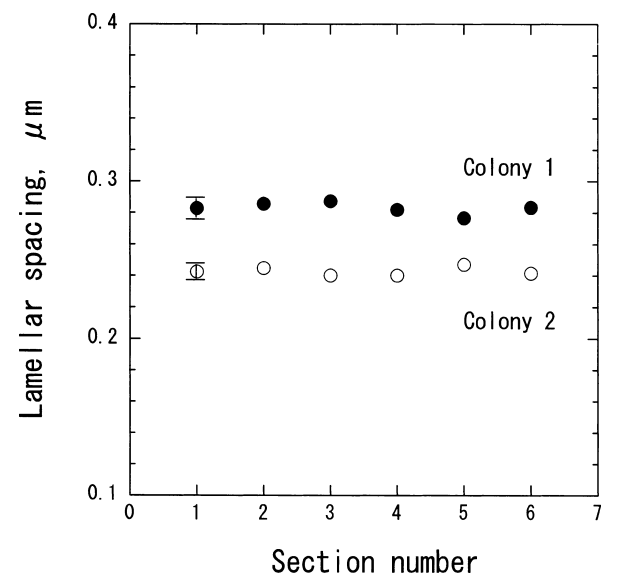

Fig. 2. Apparent lamellar spacings $\lambda_{\mathrm{a}}$ measured on consecutive planes of polish. The specimen was isothermally held at $700^{\circ} \mathrm{C}$.

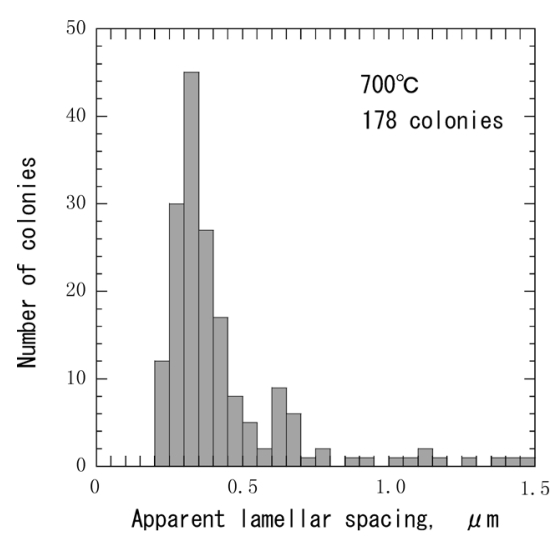

a)

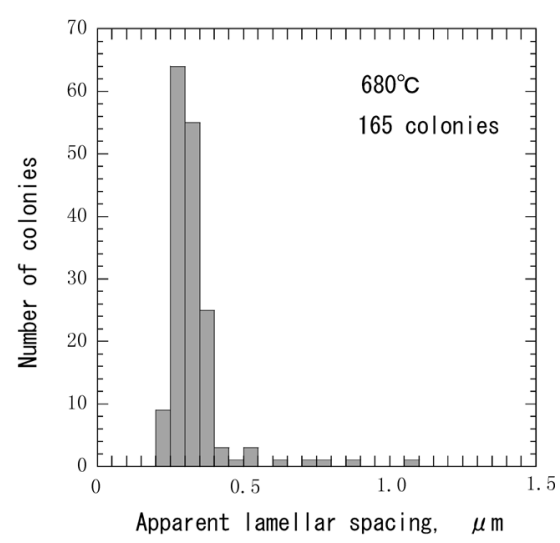

b)

Fig. 3. Frequency distributions of apparent interlamellar spacings of pearlite in the specimens isothermally reacted (a) at $700^{\circ} \mathrm{C}$ and (b) at $680^{\circ} \mathrm{C}$. The class width is $\Delta_{\lambda}=0.05 \mu \mathrm{m}$.

\subsection{Distribution of Intersection Angles of Cementite Lamellae with Metallographic Surface}

Figures 4(a) and 4(b) show two example plots of horizontal displacement $x$ against removal depth $y$, one for intermediate $\theta\left(=52.0 \pm 7.0^{\circ}\right)$ and the other, for large $\theta$ $\left(=83.1 \pm 11.3^{\circ}\right)$. When $\theta=90^{\circ}$, the lamella is perpendicular to the specimen surface. Whereas the standard deviation of the slope $\Delta m(m=x / y)$ is similar $(\sim 0.20)$, the error in the
Table 2. Measured and calculated data at two reaction temperatures.

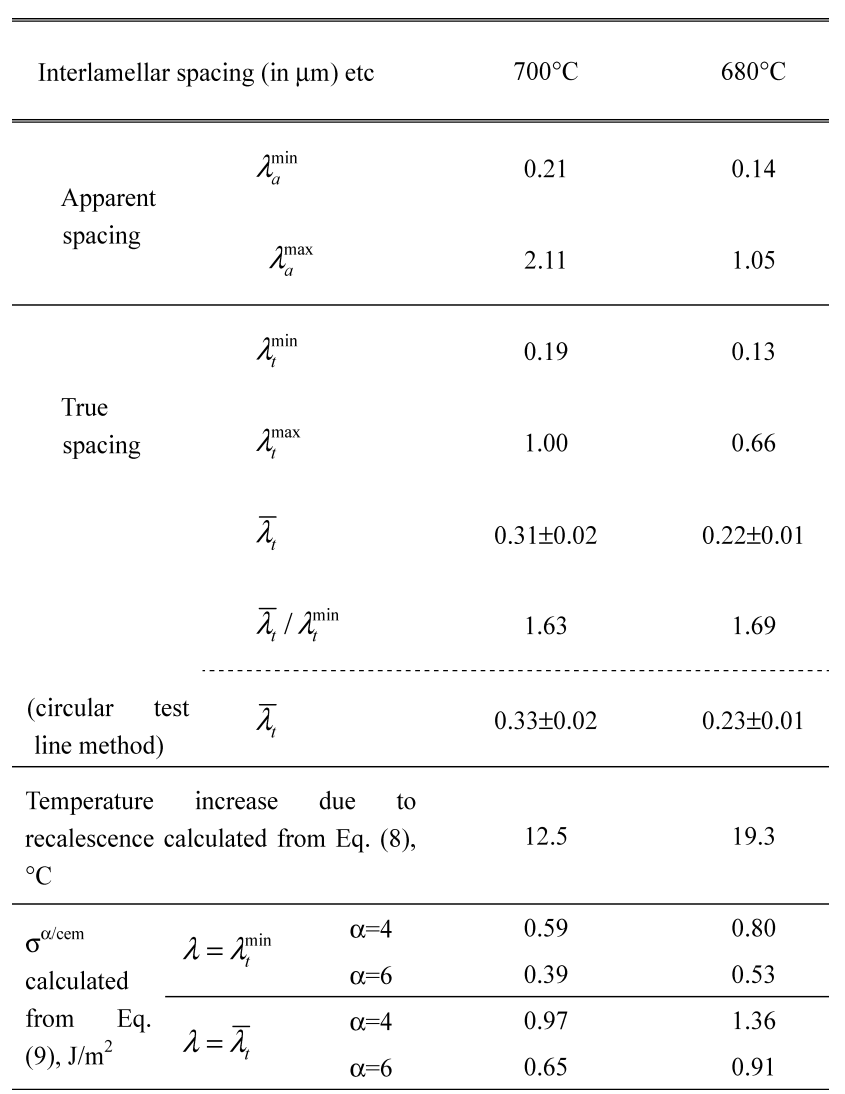

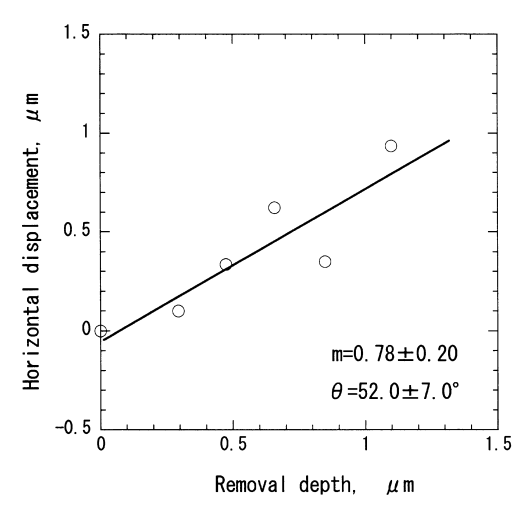

a)

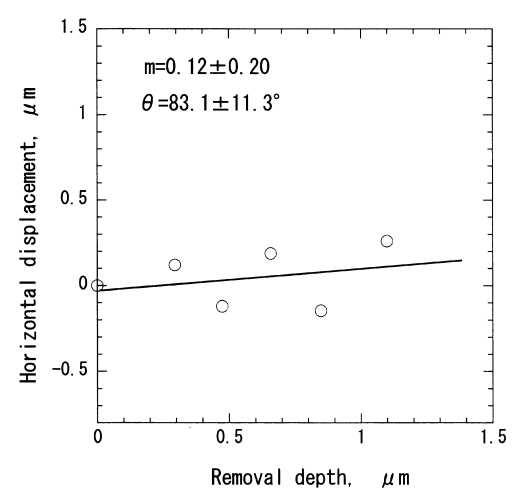

b)

Fig. 4. Example plots of horizontal displacement $x$ against removal depth $y$, (a) for intermediate intersection angle, and (b) for large intersection angle. 


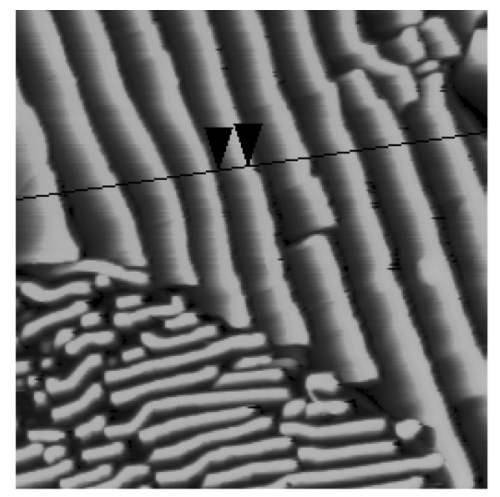

$5 \mu \mathrm{m}$

a)

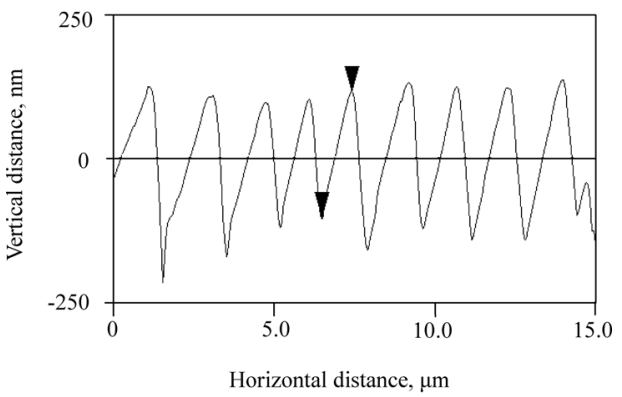

b)

Fig. 5. (a) AFM image of a colony with small intersection angle in the specimen reacted at $700^{\circ} \mathrm{C}$. (b) Topographic profile along the test line in (a)

intersection angle $\Delta \theta$ is large for the colony with the larger $\theta$. Among the total of $\sim 250$ colonies measured, quite a few exhibited an unacceptably large error range of $\theta$. Thus, about one third of colonies with larger $\Delta \theta$ in each class of $\theta$ was not included in the analysis.

An AFM image of a colony of small intersection angle of cementite lamellae is shown in Fig. 5, for which the angle was determined to be $\theta=13.1^{\circ}$. In Fig. 6 are compared the intersection angles measured by serial sectioning and AFM, for colonies whose intersection angles are $20^{\circ}<\theta<35^{\circ}$ in the specimen held at $700^{\circ} \mathrm{C}$. It is seen that the two sets of results are in broad general agreement. The distribution of intersection angle is shown in Fig. 7, the angle less than $\sim 20^{\circ}$ being measured by AFM. It is seen that the distribution varies roughly as $\sin \theta$, i.e. proportional to the solid angle at the azimuth angle $\theta$ (see also Fig. 10), which indicates that the lamellae have nearly random spatial orientations in these specimens.

\subsection{Distribution of True Interlamellar Spacing}

The frequency distributions of $\lambda_{\mathrm{t}}$ calculated from Eq. (2) are shown in Figs. 8(a) and 8(b), and the maximum $\lambda_{t}^{\max }$, minimum $\lambda_{t}^{\min }$ and mean true lamellar spacings $\bar{\lambda}_{t}$ are shown in Table 2 . It is seen that $\lambda_{\mathrm{t}}$ has a smaller scatter than $\lambda_{\mathrm{a}}$ (Figs. $3(\mathrm{a})$ and $3(\mathrm{~b})$ ). Indeed, at $700^{\circ} \mathrm{C}$ the variances of true and apparent lamellar spacings are 0.012 and $0.083 \mu \mathrm{m}^{2}$, respectively. It is also noted that the variances of $\lambda_{\mathrm{t}}$ and $\lambda_{\mathrm{a}}$ decrease to 0.0039 and $0.011 \mu \mathrm{m}^{2}$ at $680^{\circ} \mathrm{C}$. The ratios of the mean to the minimum true spacings $\bar{\lambda}_{\mathrm{t}} / \lambda_{\mathrm{t}}^{\min }$ are closer to the value (1.65) reported by Pellisier et al. ${ }^{2)}$ and

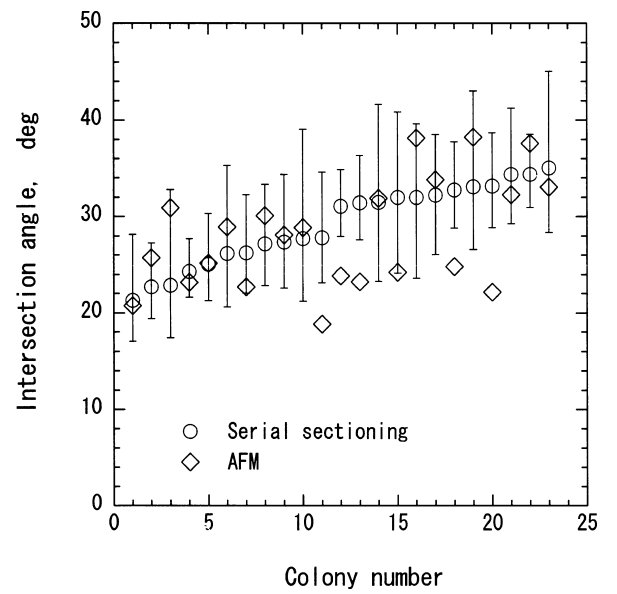

Fig. 6. Comparison of intersection angle $\theta$ determined by serial sectioning and AFM. The error bars associated with serial sectioning were calculated from the error in the slope, see Fig. 4.

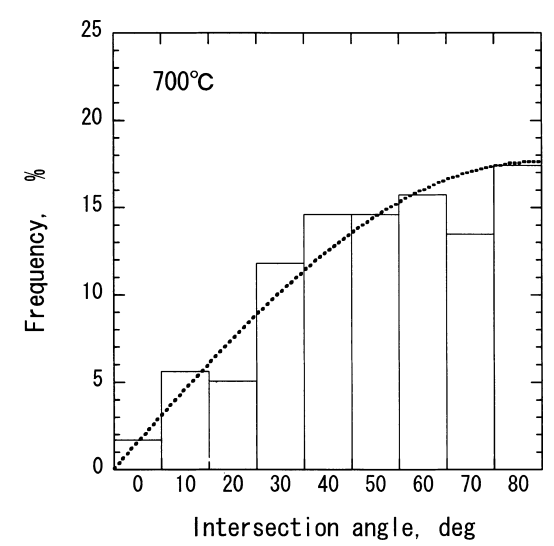

Fig. 7. Frequency distribution of intersection angles of pearlite lamellae with the metallographic surface in the specimens isothermally held at $700^{\circ} \mathrm{C}$. Dashed curves are the theoretical distribution of the angles.

the values presently obtained lie within the values reported by other authors, e.g. $\sim 1.1$ and $1.6,{ }^{5)}$ although this ratio is considered to vary significantly with alloy composition and transformation temperature.

The reciprocal of $\bar{\lambda}_{\mathrm{t}}$ and $\lambda_{\mathrm{t}}^{\mathrm{min}}$ is plotted against reaction temperature in Figs. 9(a) and 9(b), respectively. The solid line in Fig. 9(a) is due to Ridley by means of intercept spacing $^{8)}$ and to Caballero et al. by means of random spacing method $^{24)}$ in alloys containing similar concentrations of $\mathrm{Mn}$ and Si. On the other hand, the solid line in Fig. 9(b) is drawn from a large number of experimental data. ${ }^{8)}$ Both $\bar{\lambda}_{t}$ and $\lambda_{t}^{\text {min }}$ agree well with the reported data.

The following analysis was conducted to see if the distribution of apparent lamellar spacings is reproduced from the scatter of true lamellar spacings. If the lamellae in the $i$-th class of true spacing are oriented at random, the number of colonies belonging to the $k$-th class of apparent lamellar spacing $N_{k}^{i}$ is given by,

$$
N_{k}^{i}=n^{i} \int_{\phi_{k}^{i}}^{\phi_{k+1}^{i}} \cos \phi d \phi .
$$

where $\phi_{k}^{i}=\pi / 2-\theta_{k}^{i}$ is calculated from the equation, see Fig. 10, 


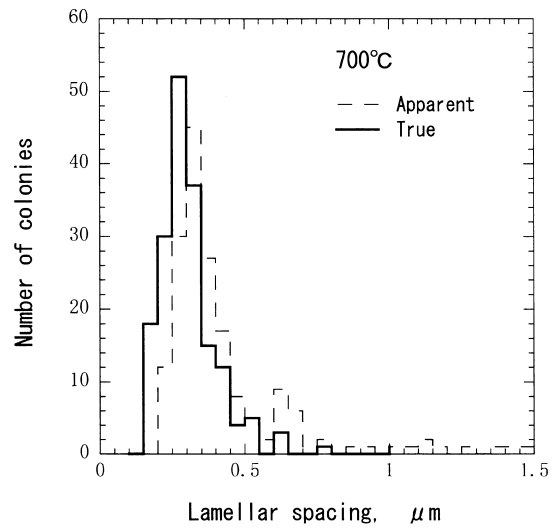

a)

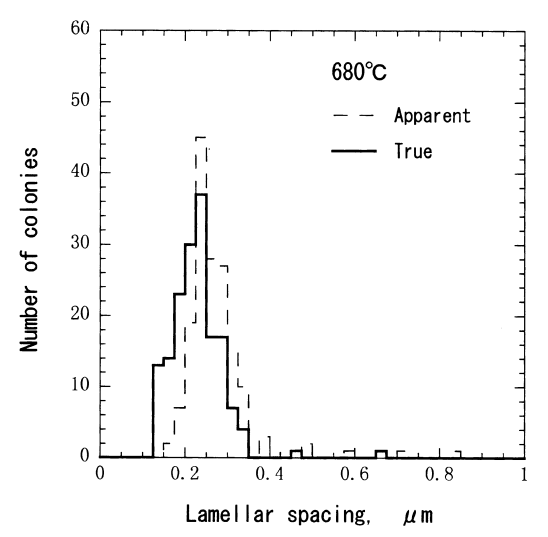

b)

Fig. 8. Frequency distributions of true interlamellar spacings $\lambda_{t}$ (solid lines) in the specimens isothermally reacted (a) at $700^{\circ} \mathrm{C}$ and (b) at $680^{\circ} \mathrm{C}$. The dashed lines are the distributions of apparent spacings reproduced from Fig. 3. The class width is $\Delta_{\lambda}=0.05 \mu \mathrm{m}$.

$$
\lambda_{\mathrm{a}}^{k}=\frac{\lambda_{\mathrm{t}}^{i}}{\cos \phi_{k}^{i}}
$$

and $\lambda_{\mathrm{t}}^{i}$ is the true lamellar spacing that characterizes the $i$ th class, and $n^{i}$ is the number of colonies belonging to that class. The number of colonies in the $k$-th class of apparent lamellar spacing $N_{k}$ can be calculated by summing the contributions from all the classes of true lamellar spacing as,

$$
N_{k}=\sum_{i=1}^{m} N_{k}^{i}
$$

where $m$ is the number of size classes. The distribution of apparent lamellar spacings at $700^{\circ} \mathrm{C}$ was calculated with $\Delta_{\lambda}=0.1 \mu \mathrm{m}$ and $m=20$, and is compared with the measured one in Fig. 11. The agreement between the calculated and measured distributions does not appear to be as good as would be expected from the agreement in the absolute values of lamellar spacing (Figs. 9(a) and 9(b)). This is probably due to a large error in the determination of intersection angle at lower angles.

\subsection{Physical Reason for the Scatter of Spacings}

The physical reasons for the scatter of true lamellar spac-

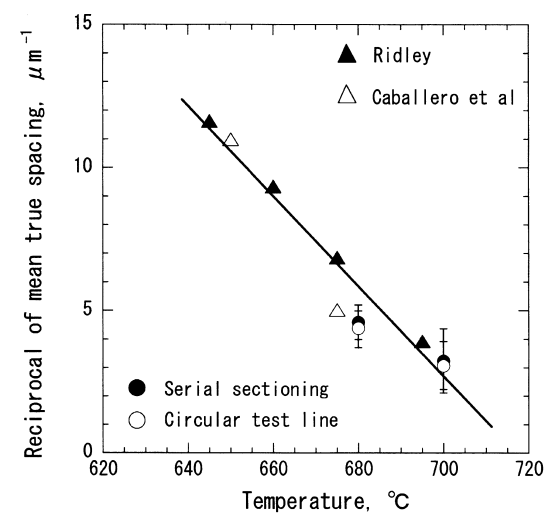

a)

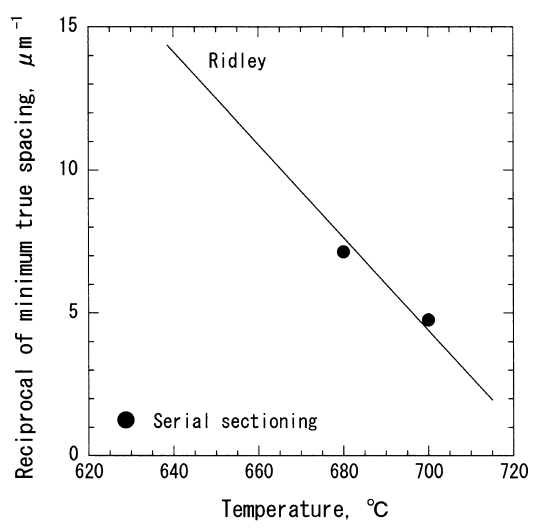

b)

Fig. 9. (a) Reciprocal of mean true interlamellar spacing plotted against transformation temperature. Solid and open triangles are due to Ridley ${ }^{8)}$ and Caballero et al. ${ }^{24)}$ (b) Reciprocal of minimum true lamellar spacing plotted against transformation temperature. Solid line is drawn from collated experimental data. ${ }^{8)}$

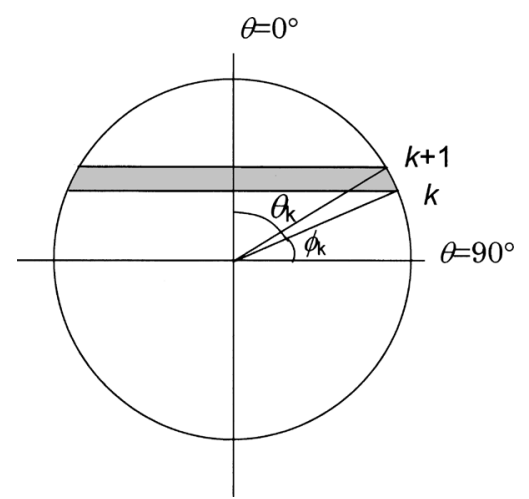

Fig. 10. Definition of the angle $\phi_{k}=\pi / 2-\theta_{k}$ that characterizes the $k$-th class of apparent lamellar spacing. The grey area is the solid angle corresponding to the azimuth angle $\theta_{k}$.

ings have been discussed by a few authors., ${ }^{3,8,25)}$ It was believed that the interlamellar spacing is affected by thermal fluctuation and/or recalescence effect. Soft impingement of carbon and possibly substitutional alloying elements between neighbouring pearlite nodules can also affect the interlamellar spacing due to slow down of growth, which is called divergent pearlite. ${ }^{26)}$ Furthermore, it was proposed that the lamellar spacing can be greater than that dictated 


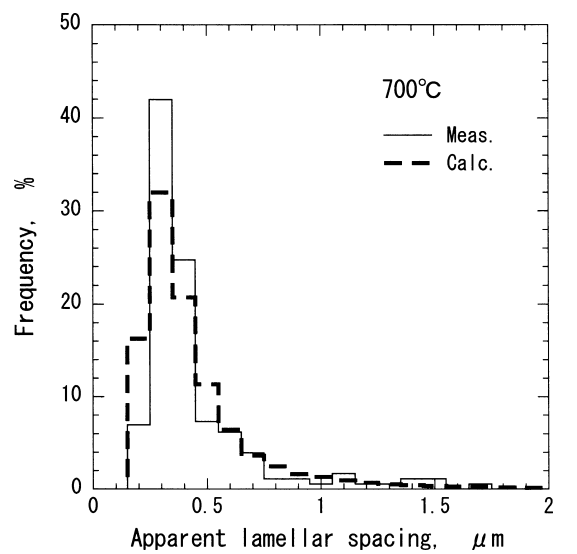

Fig. 11. Comparison of frequencies of apparent lamellar spacings calculated from the spectrum of true lamellar spacings (Fig. 8(a)) with the measured ones (Fig. 3(a)). Plotted with $\Delta_{\lambda}=0.1 \mu \mathrm{m}$.

by maximum growth rate principle if interface instability between ferrite lamellae and austenite occurs. ${ }^{27)}$ Under the assumption that the observed scatter was caused by recalescence effect and colonies having a larger true spacing were formed at a higher local temperature, the temperature at the reaction front can be calculated from the relationship,

$$
\lambda(726.3-T)=6.13 \mu \mathrm{m} \cdot{ }^{\circ} \mathrm{C} .
$$

proposed by Ridley et $a l .{ }^{8)}$ for alloys transformed at small and moderate undercoolings, for specimens transformed at 700 and $680^{\circ} \mathrm{C}$. As shown in Table 2, the temperature which would yield a lamellar spacing $\lambda=\lambda_{\mathrm{t}}$ is $10-20^{\circ} \mathrm{C}$ higher than the temperature which would produce a lamellar spacing equal to $\lambda_{t}^{\min }$. Such an increase in local temperature could occur if approximately one-tenth of the latent heat of the transformation was utilized for recalescence. It is unlikely that such a large scatter of temperature occurs by thermal fluctuation.

From the relationship proposed by Zener, ${ }^{28)}$

$$
\lambda=\frac{\alpha \sigma T_{\mathrm{E}}}{\Delta H_{\mathrm{V}}\left(T_{\mathrm{E}}-T\right)}
$$

where $\Delta H_{\mathrm{V}}\left(=607 \mathrm{MJ} / \mathrm{m}^{329)}\right)$ is the change in enthalpy per unit volume attending pearlite transformation and $T_{\mathrm{E}}$ $\left(=722^{\circ} \mathrm{C}\right)$ is the eutectoid temperature of the alloy, one can evaluate the ferrite $(\alpha)$ /cementite interfacial energy, $\sigma$. The constant $\alpha$ is equal to 4 if the pearlite growth is rate-controlled by volume diffusion of carbon in austenite and the maximum growth rate principle operates for the growth of pearlite. Two sets of $\sigma$ values were calculated assuming that the true interlamellar spacing is $\lambda=\lambda_{\mathrm{t}}^{\mathrm{min}}$ and $\lambda=\bar{\lambda}_{\mathrm{t}}$. If the principle of maximum entropy production is operative $\alpha$ is equal to 6 , which reduces the calculated $\sigma$ values considerably. It was also shown that measured growth rates of pearlite nodule are faster than those calculated assuming volume diffusion of carbon in plain carbon eutectoid steel ${ }^{30}$ ) and this is attributed to the boundary diffusion of carbon between the pearlite nodule and the austenite matrix. If it is the case, $\alpha$ is equal to 3 and 4 for the maximum growth rate and maximum entropy production criteria, respectively, which somewhat increases the $\sigma$ values from those calculated assuming carbon volume diffusion in Table 2 . In view of the range of $\sigma$ values so far reported, e.g. 0.40 to $\sim 0.7 \mathrm{~J} / \mathrm{m}^{2},{ }^{29,31)}$ the mean spacing $\bar{\lambda}_{\mathrm{t}}$ yields a somewhat too large $\alpha /$ cem interfacial energy. Furthermore, Mellor and Edmond $^{32)}$ reported that the lamellar spacing of pearlite increased in a specimen thicker than $1 \mathrm{~mm}$ in eutectoid steel (compared to a specimen of $0.15 \mathrm{~mm}$ ), the effect becoming progressively larger at larger undercoolings. Thus, it is likely that recalescence had a significant influence on the distribution of lamellar spacings presently observed.

\section{Conclusions}

The interlamellar spacings of pearlite formed isothermally at 700 and $680^{\circ} \mathrm{C}$ in a near-eutectoid $\mathrm{Fe}-0.82$ mass $\% \mathrm{C}$ alloy were measured by serial sectioning coupled with scanning electron microscopy and atomic force microscopy. The intersection angle of cementite lamellae was determined from the ratio of horizontal displacements to the removal depths over several sections, from which the distribution of true lamellar spacings was experimentally determined. Both the mean and minimum true spacings were in good agreement with the literature. The distribution of lamellar spacing on the metallographic surface, calculated from the measured spectrum of true lamellar spacings was in fair agreement with the measured one. This technique permits measurement of pearlite lamellar spacing to be made with reasonable accuracy. It is likely that the scatter of true lamellar spacing is primarily due to recalescence, rather than thermal fluctuation, although interface instability and the presence of substructure and associated stress/strain fields can cause the change in spacing and orientation of pearlite lamellae during transformation.

\section{Acknowledgements}

One of the authors (G. H. Zhang) acknowledges financial support from the Ministry of Education, Culture, Sports, Science and Technology, Japanese government. The authors express their thanks to Dr. Adachi, Senior Research Scientist, and Mr. Yoshida, student, National Institute for Materials Science, for valuable comments and assistance with experiment.

\section{REFERENCES}

1) N. T. Belaiew: J. Iron Steel Inst., 105 (1922), 201.

2) G. E. Pellisier, M. F. Hawkes, W. A. Johnson and R. F. Mehl: Trans. Am. Soc. Met., 30 (1942), 1049

3) M. Gensamer, E. B. Pearsall, W. S. Pellini and J. R. Low: Trans. Am. Soc. Met., 30 (1942), 983.

4) M. K. Asundi and D. F. R. West: J. Inst. Met., 94 (1966), 19.

5) G. Birkbeck and T. C. Wells: Trans. AIME, 242 (1968), 2217.

6) B. G. Mellor and D. V. Edmonds: Metall. Trans. A, 8A (1977), 763.

7) A. Roosz, Z. Gacsi and M. K. Baan: Metallography, 13 (1980), 299.

8) N. Ridley: Metall. Trans. A, 15A (1984), 1019.

9) J. F. Tilbury, T. D. Mottishaw and G. D. W. Smith: Metallography, 19 (1980), 243.

10) D. S. Zhou and G. J. Shiflet: Metall. Trans. A, 23A (1992), 1259.

11) M. De. Graef, M. V. Kral and M. Hillert: JOM, 58 (2006), No. 11, 25.

12) Y. Adachi, S. Morooka, K. Nakajima and Y. Sugimoto: Acta Mater., 56 (2008), 5995.

13) D. Brown and N. Ridley: J. Iron Steel Inst., 204 (1966), 811.

14) E. E. Underwood: Quantitative Stereology, Addison-Wesley, Reading, Massachusetts, (1970), 73.

15) G. F. Vander Voort and A. Roosz: Metallography, 17 (1984), 1. 
16) A. Roosz and Z. Gacsi: Metallography, 14 (1981), 129.

17) H. S. Fong: Metallography, 23 (1989), 173.

18) V. T. L. Buono, B. M. Gonzalez, T. M. Lima, M. S. Andrade: J. Mater. Sci., 32 (1997), 1005.

19) M. V. Kral, M. A. Mangan, G. Spanos and R. O. Rosenberg: Mater Charact., 45 (2000), 17.

20) M. Enomoto: Tetsu-to-Hagané, 90 (2004), 183.

21) R. T. DeHoff: J. Microsc., 131 (1983), 259.

22) M. Enomoto, K. M. Wu, Y. Inagawa, T. Murakami and S. Nanba: ISIJ Int., 45 (2005), 756.

23) P. R. Howell: Mater. Charact., 42 (1998), 227.

24) F. G. Caballero, C. Garcia de Andres and C. Capdevila: Mater. Charact., 45 (2000), 111.
25) P. G. Boswell and G. A. Chadwick: Acta Metall., 25 (1977), 779.

26) J. W. Cahn and W. C. Hagel: Acta Metall., 11 (1963), 561.

27) S. D. Kulkarni: Acta Metall., 21 (1973), 1539.

28) C. Zener: Trans. AIME, 47 (1946), 550.

29) J. J. Kramer, G. M. Pound and R. F. Mehl: Acta Metall., 6 (1958), 763.

30) J. W. Cahn and W. C. Hagel: Decomposition of Austenite by Diffusional Processes, ed. by V. F. Zackay and H. I. Aaronson, Interscience Publishers, New York, (1962), 131.

31) H. O. Kirchner, B. G. Mellor and G. A. Chadwick: Acta Metall., 26 (1978), 1023.

32) B. G. Mellor and D. V. Edmonds: Metall. Trans. A, 8A (1977), 773. 